\title{
EL IHOS Y CPOD Y SU RELACIÓN CON EL PH SALIVAL EN ALUMNOS CON HABILIDADES DIFERENTES CON RETARDO MENTAL DEL CENTRO ANN SULLIVAN DEL PERÚ
}

\author{
THE OHI-S AND DMFT INDEX AND THEIR RELATIONSHIP WITH SALIVARY PH IN \\ STUDENTS WITH SPECIAL NEEDS WITH INTELLECTUAL DISABILITIES AT THE ANN \\ SULLIVAN CENTER IN PERU
}

Luis Angel Limo Dávila1a

\section{RESUMEN}

Objetivo: La alteración de la capacidad buffer de la saliva podría estar asociada a la susceptibilidad de un individuo con habilidades diferentes en desarrollar caries dental. Este estudio buscó determinar la relación entre el índice de Higiene Oral Simplificado (IHOS), el Índice CPOD y el pH salival de los alumnos con habilidades diferentes con retardo mental del Centro Ann Sullivan del Perú (CASP). Material y Métodos: Estudio transversal, prospectivo y clínico. 45 alumnos del CASP, entre 10 y 50 años de edad, fueron evaluados para obtener sus IHOS y sus Índices CPOD a través de un odontograma y ph salival. A cada alumno se le pidió una muestra de $6 \mathrm{ml}$ de saliva no estimulada para medir su pH mediante la utilización de un Phmetro digital. Resultados: Se encontró un IHOS de 2.0 equivalente a un índice regular; y un CPOD muy bajo de 0.30 , según la categorización de la Organización Mundial de la Salud. Los rangos de pH registrados fueron en su mayoría de 7.7. Se aplicó la prueba paramétrica de Anova y se obtuvo un valor de $p=0,362$ para la relación entre el IHOS y el $\mathrm{pH}$ salival, y de $(\mathrm{p}=0,280)$ para la relación del ph salival con el Índice CPOD. Conclusiones: No existe diferencia entre el IHOS, el CPOD y el pH salival de los alumnos con habilidades diferentes con retardo mental del CASP. Por tanto, su estado de salud podría estar más asociado a problemas psicomotrices propios de su condición.

Palabras clave: Personas con discapacidad dental; saliva; Índice de higiene oral; indice de placa dental. (Fuente: DeCS BIREME).

\begin{abstract}
Objective: Salivary buffering capacity might be related to an individual's susceptibility to Dental Caries. Aim: to find the association between the Oral Hygiene Index Simplified by Green \& Vermillion (OHI-S) and the DMFT Index, and the salivary $\mathrm{pH}$ among students with special needs mentally retarted of the Center Ann Sullivan of Peru (CASP). Materials and Methods: A cros-sectional, prospective and clinical study was conducted in 45 students among 10 and 50 years old, who atended to the CASP, were assesed to determine the index of decayed, missing and filled teeth (DMFT Index) and plaque scores by OHI-S by Greene \& Vermillion. 45 samples of saliva were collected, as a mínimum of $6 \mathrm{ml}$. in order to measure its $\mathrm{pH}$ and buffer rate, by using a digital PHmeter. Results: for the whole group, it was registered a OHI-S = 2.0 which equals to a regular index; and a DMFT very low according to the World Health Organization. Ph rated were average 7.7. Though ANOVA parametric test, with a confidence level of $95 \%$, it was determined a level of significance of 0.362 was determined for the relationship between the $\mathrm{OHI}-\mathrm{S}$ and the salivary $\mathrm{pH}$, and a level of 0.280 for the relationship between the DFMT Index and rhe salivary $\mathrm{pH}$ of the students attending to the CASP. Conclusions: Oral higiene status might be more related to their psychomotor disabilities.
\end{abstract}

Key words: Dental Plaque Index; Dental Health Surveys; Saliva; Intellectual Disability. (Source: MeSHNLM).

${ }^{1}$ Universidad Nacional Mayor de San Marcos
${ }^{a}$ Cirujano Dentista.

Correspondencia:

Luis Angel Limo Dávila

Teléfono 051-995143749

Correo electrónico: luis.Id@live.com
Este es un artículo Open Access distribuido bajo la licencia Creative Commons Atribución-NoComercialCompartirlgual 4.0

Citar como: Limo - Dávila L. El IHOS y CPOD y su relación con el pH salival en alumnos con habilidades diferentes con retardo mental del centro Ann Sullivan del Perú. KIRU. 2017;14(1):35-45. https://doi.org/10.24265/kiru.2017.v14n1.05 


\section{INTRODUCCIÓN}

Se entiende por 'discapacidad' la pérdida o limitación de oportunidades para desarrollar una vida normal, con derechos y deberes equitativos entre los miembros de una comunidad debido a barreras físicas y psicosociales ${ }^{(1)}$. En personas con habilidades diferentes, como el retraso mental, se ha determinado que la predisposición a desarrollar una enfermedad periodontal, una caries dental, hábitos parafuncionales, etc. no difiere de la de individuos sin esa condición o con habilidades normales ${ }^{(2,3)}$. En ese sentido, el factor principal relacionado con tener un perfil de salud bucal pobre (con presencia de caries dental, enfermedad periodontal, etc.) es la inadecuada remoción de placa bacteriana de las superficies de las piezas dentales ${ }^{(4)}$

Sin embargo, limitaciones neuromusculares y problemas de coordinación motora en individuos con alguna discapacidad mental podrían estar directamente vinculados con una salud bucal pobre $^{(5)}$

En este escenario, la saliva juega un rol bastante significativo, pues es necesaria para la protección y lubricación de los tejidos de la mucosa bucal, remineralización de las piezas dentales, digestión, estimulación del sentido del sabor, así como el balance de su $\mathrm{pH}$ y fonación. La saliva es usada incluso para el diagnóstico no invasivo de diversas enfermedades debido a su fácil obtención y confiable manejo ${ }^{(5,6)}$. El balance del $\mathrm{pH}$ salival es mantenido por el equilibro del ácido carbónico y los sistemas de bicarbonato, fosfato y sistema proteico del organismo. En atención a ello, la saliva debe mantener un $\mathrm{pH}$ neutro, es decir de 6,5. Esta capacidad "tamponadora" del medio al neutralizar el medio ácido producido tras la comida, evita la desmineralización del esmalte dental y la acumulación de placa bacteriana, que se produce con un $\mathrm{pH}$ básico ${ }^{(7)}$. De allí la importancia de conocer la alcalinidad de la saliva de las personas con habilidades diferentes y saber su susceptibilidad y/o predisposición a desarrollar caries dental y enfermedades periodontales ${ }^{(8,9)}$.

La capacidad buffer o tampón de la saliva podría estar relacionada con la susceptibilidad de un individuo a desarrollar caries dental. Aquí el pH cumple un rol fundamental al mantener el equilibrio ácido-alcalino en boca, de forma tal que se evite la desmineralización del esmalte dental ${ }^{(10,11)}$. En personas con habilidades diferentes, estos rangos de $\mathrm{pH}$ podrían estar alterados debido a su condición. Asimismo existen muchas variables y factores que podrían intervenir en el estado de salud oral de las personas con habilidades diferentes, más aun si presentan retardo mental, tales como un coeficiente intelectual bajo, o por la falta de habilidad motriz que pueden tener como parte de su propia condición ${ }^{(11,12)}$. Sin embargo, no hay estudios recientes en nuestro país que tomen en cuenta la capacidad buffer de saliva en personas con dichas características ${ }^{(13)}$.

El presente estudio relacionó el estado de salud oral a través de los Índices de Higiene Oral Simplificado, según Greene \& Vermillion, y el Índice CPOD para registrar el número de piezas dentales permanentes cariadas, perdidas y obturadas de los alumnos con habilidades diferentes con retardo mental del Centro Ann Sullivan del Perú, con su pH salival.

\section{MATERIAL Y MÉTODO}

El estudio fue de tipo descriptivo, transversal, retrospectivo y clínico ya que se realizó mediante la inspección directa de la cavidad bucal de los sujetos de estudio. La población estuvo conformada por alumnos con habilidades diferentes con retardo mental del Centro Ann Sullivan del Perú (CASP) pertenecientes al año escolar 2013. La muestra estuvo conformada por cuarenta y cinco (45) alumnos mayores y menores de edad, cuyos padres accedieron a participar del estudio mediante la aprobación del consentimiento informado. Así, los alumnos y sus respectivos padres asistieron a una charla inicial de sensibilización para obtener información sobre el propósito del estudio. La técnica de muestreo utilizada fue no probabilística y el procedimiento para obtener el pH salival consistió en pedir a los alumnos que escupan o babeen en un vaso de precipitados, aproximadamente entre $10 \mathrm{y}$ 30 milímetros de saliva no estimulada. Luego de ello se utilizó un phmetro digital para medir el pH de la muestra obtenida.

La técnica consistió en colocar la punta del phmetro en una solución buffer con pH de 4.0 durante 10 segundos; luego se ajustó el phmetro digital con la varilla calibradora hasta llegar al rango exacto de 4.0. Se repitió el proceso con una solución buffer con $\mathrm{pH}$ de 7.0, luego se colocó la punta del cátodo en el recipiente que contenía la muestra salival, se esperó 10 segundos hasta que arroje un rango exacto. Entre cada extracción de muestra de saliva se colocó la punta del aparato en un vaso de precipitados que contenía $30 \mathrm{ml}$. de agua destilada, hasta que cubrió toda la punta por 30 segundos, con la finalidad de eliminar cualquier tipo de impurezas dejadas por la muestra anterior. Finalmente, los resultados se registraron en una ficha de recolección de datos previamente diseñada.

Teniendo en cuenta todas las medidas de bioseguridad, se obtuvo el Índice CPOD mediante la inspección clínica, realizando un registro de datos 
en un odontograma, el cual consistió en considerar las piezas dentales cariadas, perdidas por caries y obturadas, tomando como unidad al diente. Los valores clasificados para este índice se basaron en lo establecido por la OMS, el mismo que resulta de la sumatoria de piezas dentarias permanentes cariadas, perdidas por caries y obturadas ${ }^{(14,15)}$. Al respecto, la cuantificación es la siguiente:

Tabla 1. Escala de puntuación para registrar el Índice CPOD.

\begin{tabular}{ll} 
PUNTUACIÓN & CATEGORIZACIÓN \\
\hline De 0,0 a 1,1 & Muy Bajo \\
De 1,2 a 2,6 & Bajo \\
De 2,7 a 4,4 & Moderado \\
De 4,5 a 6,5 & Alto
\end{tabular}

De otro lado, para obtener el Índice de Higiene Oral Simplificado (IHOS) según Greene \& Vermillion, se aseguró que los alumnos no hayan consumido ningún alimento por lo menos 2 horas antes de registrar el índice; para ello se empleó púrpura de Genciana, la cual se aplicó mediante un hisopo en las superficies vestibulares de las piezas 1.1, $1.6 \mathrm{y}$ 2.6, y sobre las linguales en las piezas 4.6,3.6 y 3.1. Para el caso de dentición mixta, se consideraron las caras vestibulares de las piezas deciduas $5.1,5.5$ y 6.5; y las linguales de las piezas $7.1,7.5$ y $8.5^{(16,17)}$. Luego de ello se promedió el IHOS dividiendo la sumatoria de los códigos asignados a las piezas entre el número de dientes examinados. Al respecto se presenta el siguiente detalle:

Para depósitos blandos y duros:

0 : No hay depósitos ni pigmentaciones.

1: Existen depósitos o tártaro supragingival que cubre no más de $1 / 3$ de la superficie dental.

2: Existen depósitos o tártaro supragingival que cubre más de $1 / 3$, pero menos de $2 / 3$ de la superficie dentaria.

3: Los depósitos o tártaro supragingival cubre más de 2/3 de la superficie dental, o existe una banda gruesa continua de tártaro supragingival que rodea la porción cervical del diente.

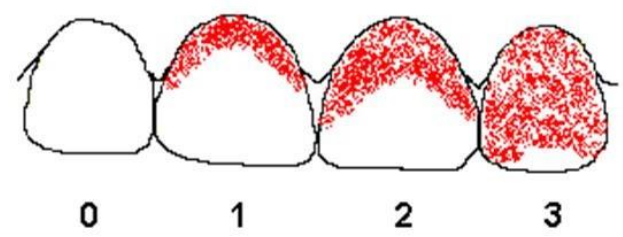

Figura 1. Referencia de valoración para el IHOS según Greene y Vermillion ${ }^{(17)}$.

Para realizar el cálculo de este índice, se divide la sumatoria de los códigos asignados a las piezas dentales entre el número de piezas examinadas:

\section{ÍNDICE = SUMA DE CÓDIGOS / Nro. DIENTES}

Los resultados se valoran de la siguiente manera:

Tabla 2. Escala de puntuación para registrar el IHOS (Greene y Vermillion)

\section{PUNTUACIÓN}

De 0,0 a 1,0

De 1,1 a 2,0

De 2,1 a 3,1

Mayor a 3,1

Los instrumentos de medición descritos en los párrafos anteriores fueron aplicados en una sola sesión y bajo las mismas condiciones. Asimismo, la intervención se llevó a cabo con la asesoría del jefe del Departamento de Odontología del CASP, así como con la ayuda de docentes y auxiliares de educación del plantel, y en algunos casos, los padres de familia participaron con la finalidad de facilitar la intervención.

Conviene indicar que para la intervención se tomaron en cuenta todos los aspectos éticos respectivos. Por ello se solicitaron todos los permisos correspondientes a las autoridades pertinentes del CASP. De otro lado y de forma paralela, el investigador pasó por un proceso de entrenamiento en las aulas y durante las clases del CASP, así como en otras actividades del Centro Ann Sullivan del Perú, con la finalidad de familiarizarse y sensibilizarse con los alumnos y conocer el manejo de conducta de los mismos.

Finalmente, la información fue analizada y ordenada en porcentaje y frecuencia mediante tablas y gráficos de distribución de datos. En ese sentido, la relación de las variables se obtuvo mediante un programa estadístico SPSS, versión 21.0, y la técnica estadística usada para el análisis de la información fue una prueba paramétrica de Anova con un nivel de confianza de $95 \%$.

\section{RESULTADOS}

Conforme se indicó en los párrafos precedentes, la muestra estuvo conformada por 45 alumnos del CASP, de los cuales 29 fueron hombres y 16 mujeres, cuyo porcentaje representativo de la muestra fue de $64,4 \%$ y $35,6 \%$, respectivamente. Asimismo, se observó que el $11,1 \%$ de la muestra estuvo conformada por alumnos de 29 años de edad, siendo esta edad la más representativa de la muestra. 
Además, del total de la muestra, 6 alumnos registraron $\mathrm{PH}$ salival de 7,5 y otros 6 alumnos un $\mathrm{pH}$ salival de 7,9. Dichos $\mathrm{pH}$ fueron los más representativos de la muestra ambos representando un $13,3 \%$ cada uno. Así mismo, se observó que el rango de $\mathrm{pH}$ salival más ácido registrado en los alumnos tuvo un valor de 6,3, representando al $2,2 \%$ del total de la muestra. Del mismo modo, el rango de $\mathrm{PH}$ salival más alcalino registrado tuvo un valor de 8,3 , registrado en dos alumnos de la muestra, los que representan el $4,4 \%$ de la población de la muestra.

A continuación se presentan los cuadros de resultados:

Tabla 3. pH salival de los alumnos con habilidades diferentes con retardo mental del CASP - 2013.

\begin{tabular}{ccccc}
\hline $\begin{array}{c}\text { pH } \\
\text { SALIVAL }\end{array}$ & FRECUENCIA & $\%$ & $\begin{array}{c}\% \\
\text { VÁLIDO }\end{array}$ & $\begin{array}{c}\% \\
\text { ACUMULADO }\end{array}$ \\
\hline $\mathbf{6 , 3 0}$ & 1 & $2,2 \%$ & $2,2 \%$ & $2,2 \%$ \\
$\mathbf{6 , 4 0}$ & 1 & $2,2 \%$ & $2,2 \%$ & $4,4 \%$ \\
$\mathbf{6 , 8 0}$ & 2 & $4,4 \%$ & $4,4 \%$ & $8,9 \%$ \\
$\mathbf{6 , 9 0}$ & 3 & $6,7 \%$ & $6,7 \%$ & $15,6 \%$ \\
$\mathbf{7 , 1 0}$ & 4 & $8,9 \%$ & $8,9 \%$ & $24,4 \%$ \\
$\mathbf{7 , 2 0}$ & 1 & $2,2 \%$ & $2,2 \%$ & $26,7 \%$ \\
$\mathbf{7 , 3 0}$ & 4 & $8,9 \%$ & $8,9 \%$ & $35,6 \%$ \\
$\mathbf{7 , 5 0}$ & 6 & $13,3 \%$ & $13,3 \%$ & $48,9 \%$ \\
$\mathbf{7 , 6 0}$ & 1 & $2,2 \%$ & $2,2 \%$ & $51,1 \%$ \\
$\mathbf{7 , 7 0}$ & 2 & $4,4 \%$ & $4,4 \%$ & $55,6 \%$ \\
$\mathbf{7 , 8 0}$ & 1 & $2,2 \%$ & $2,2 \%$ & $57,8 \%$ \\
$\mathbf{7 , 9 0}$ & 6 & $13,3 \%$ & $13,3 \%$ & $71,1 \%$ \\
$\mathbf{8 , 0 0}$ & 5 & $11,1 \%$ & $11,1 \%$ & $82,2 \%$ \\
$\mathbf{8 , 1 0}$ & 4 & $8,9 \%$ & $8,9 \%$ & $91,1 \%$ \\
$\mathbf{8 , 2 0}$ & 2 & $4,4 \%$ & $4,4 \%$ & $95,6 \%$ \\
$\mathbf{8 , 3 0}$ & 2 & $4,4 \%$ & $4,4 \%$ & $100,0 \%$ \\
TOTAL & 45 & 100,0 & $100,0 \%$ & \\
& & $\%$ & &
\end{tabular}

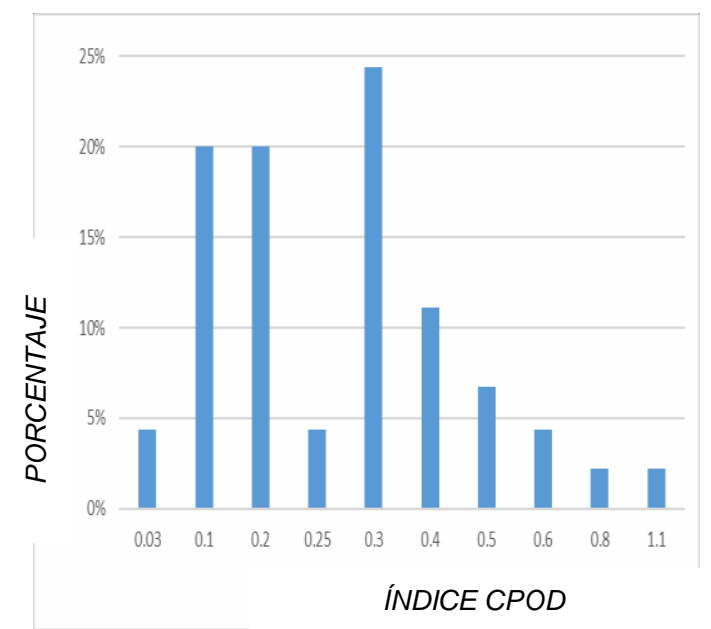

Figura 2. Índice CPOD de los alumnos con habilidades diferentes con retardo mental del CASP - 2013.
En la figura 2 se puede observar los rangos, frecuencias y porcentajes del Índice de piezas cariadas, perdidas y obturadas (CPOD) de los alumnos que participaron del estudio. En ella se muestra que el $24,4 \%$ de los alumnos con habilidades diferentes con retardo mental del CASP presentó un CPOD de 0,3 equivalente a un índice CPOD "Muy Bajo", conforme a los parámetros determinamos por la $\mathrm{OMS}^{(34)}$. Dicho resultado fue obtenido en 11 de los 45 alumnos que participaron del presente estudio.

De otro lado, el menor rango COPD obtenido en el estudio fue de 0,03 , y fue registrado en 2 alumnos de la muestra, quienes representaron al $4,4 \%$ de la población de la muestra. Dicho resultado es considerado también como un índice CPOD "Muy Bajo" conforme a los parámetros determinados por la OMS.

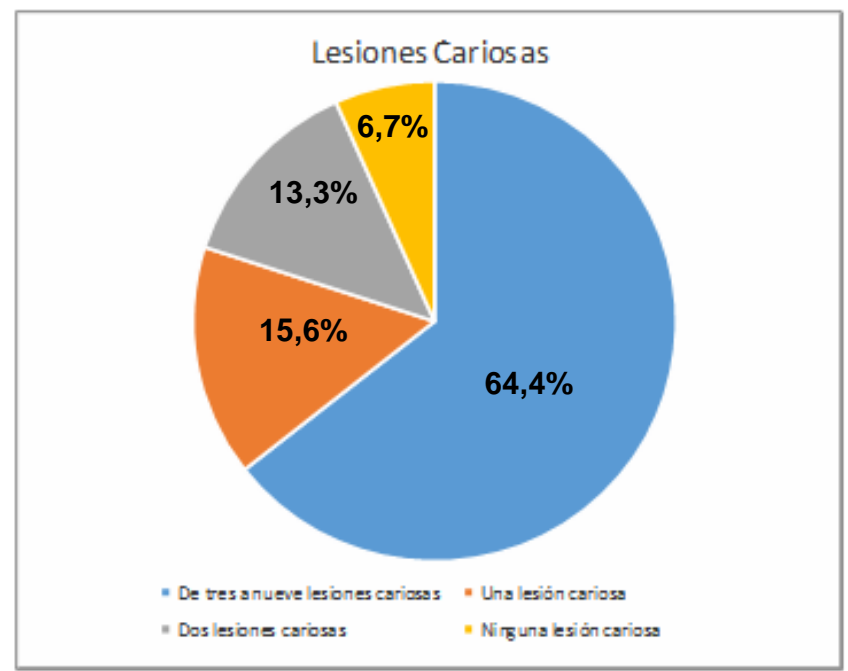

Figura 3. Piezas cariadas de los alumnos con habilidades diferentes con retardo mental del CASP - 2013.

En la figura 3 se muestra que el $6,7 \%$ del total de la población que participó en el estudio no presentó ninguna lesión cariosa. Dicho resultado se presentó en 3 alumnos del total de la muestra. Asimismo, en 7 alumnos de la muestra se registró una sola lesión cariosa, cuyo resultado representó el $15,6 \%$ de la población muestreada.

El 64,4\% de los alumnos tuvo más de 2 lesiones cariosas; siendo 14 el máximo número de lesiones cariosas registradas en una cavidad bucal.

En conclusión, si bien estos resultados reflejan que, a pesar de que el $24,4 \%$ de los alumnos que participaron en el estudio obtuvieron un índice 
CPOD muy bajo, en la mayoría se registró más de dos lesiones cariosas, por lo que se requieren medidas de tratamiento oportunas y preventivas.

En la tabla 4 se evidencia que el grupo poblacional del estudio registró valores IHOS (según OMS) de
1,1 hasta 2,0. Estos valores alcanzaron una sumatoria porcentual de $37,7 \%$, siendo la categoría de IHOS regular la de mayor representatividad en este estudio. De igual forma, el valor IHOS registrado con mayor frecuencia fue de 2,0, que representa al $8,9 \%$ del total de la muestra.

Tabla 4. Índice Higiene Oral Simplificado (IHOS) de los alumnos con habilidades diferentes con retardo mental del CASP - 2013.

\section{CATEGORIZACIÓN VALOR IHOS FRECUENCIA PORCENTAJE PORCENTAJE}

\begin{tabular}{|c|c|c|c|c|}
\hline \multirow{3}{*}{ IHOS ÓPTIMO } & & & & ACUMULADC \\
\hline & 0,7 & 3 & $6,70 \%$ & $6,70 \%$ \\
\hline & 1 & 1 & $2,20 \%$ & $8,90 \%$ \\
\hline \multirow[t]{7}{*}{ IHOS REGULAR } & 1,1 & 2 & $4,40 \%$ & $13,30 \%$ \\
\hline & 1,3 & 2 & $4,40 \%$ & $17,80 \%$ \\
\hline & 1,5 & 3 & $6,70 \%$ & $24,40 \%$ \\
\hline & 1,6 & 2 & $4,40 \%$ & $28,90 \%$ \\
\hline & 1,7 & 3 & $6,70 \%$ & $35,60 \%$ \\
\hline & 1,9 & 1 & $2,20 \%$ & $37,80 \%$ \\
\hline & 2 & 4 & $8,90 \%$ & $46,70 \%$ \\
\hline \multirow[t]{7}{*}{ IHOS MALO } & 2,1 & 1 & $2,20 \%$ & $48,90 \%$ \\
\hline & 2,3 & 1 & $2,20 \%$ & $51,10 \%$ \\
\hline & 2,4 & 1 & $2,20 \%$ & $53,30 \%$ \\
\hline & 2,5 & 3 & $6,70 \%$ & $60,00 \%$ \\
\hline & 2,6 & 1 & $2,20 \%$ & $62,20 \%$ \\
\hline & 2,8 & 2 & $4,40 \%$ & $66,70 \%$ \\
\hline & 3 & 1 & $2,20 \%$ & $68,90 \%$ \\
\hline \multirow[t]{11}{*}{ IHOS MUY MALO } & 3,2 & 2 & $4,40 \%$ & $73,30 \%$ \\
\hline & 3,3 & 1 & $2,20 \%$ & $75,60 \%$ \\
\hline & 3,5 & 3 & $6,70 \%$ & $82,20 \%$ \\
\hline & 3,8 & 1 & $2,20 \%$ & $84,40 \%$ \\
\hline & 4 & 2 & $4,40 \%$ & $89,90 \%$ \\
\hline & 4,3 & 1 & $2,20 \%$ & $91,10 \%$ \\
\hline & 4,5 & 1 & $2,20 \%$ & $93,30 \%$ \\
\hline & 4,6 & 1 & $2,20 \%$ & $95,60 \%$ \\
\hline & 4,8 & 1 & $2,20 \%$ & $97,80 \%$ \\
\hline & 6 & 1 & $2,20 \%$ & $100,00 \%$ \\
\hline & TOTAL & 45 & $100,00 \%$ & \\
\hline
\end{tabular}

En la tabla 5 se relacionó el Índice de Higiene Oral Simplificado según Greene \& Vermillion con el pH salival de los alumnos con habilidades diferentes con retardo mental del Centro Ann Sullivan del Perú. Mediante el software estadístico SPSS 21.0 se contrastó ambas variables del IHOS (Greene \& Vermillion) con el pH salival de la población mediante la prueba paramétrica ANOVA con un nivel de confianza de $95 \%$. Respecto de lo cual se obtuvo un nivel de significancia $p$ de 0,362 con una desviación de 0,31 ; es decir, no existe diferencia significativa entre ambas variables ya que $p$ fue mayor a 0,05 . 
Tabla 5. Relación del IHOS y el pH salival de los alumnos con habilidades diferentes con retardo mental del CASP 2013.

ANOVA de un factor

\begin{tabular}{|c|c|c|c|c|c|c|c|}
\hline & & & $\begin{array}{c}\text { Suma de } \\
\text { cuadrados }\end{array}$ & GI & $\begin{array}{c}\text { Media } \\
\text { cuadrática }\end{array}$ & $\mathrm{F}$ & Sig. \\
\hline \multirow{5}{*}{$\begin{array}{l}\text { INDICE DE } \\
\text { HIGIENE } \\
\text { ORAL (Greene } \\
\text { \& Vermillion) }\end{array}$} & Inter-grupos & (Combinados) & 125.495 & 9 & 13.944 & .500 & .864 \\
\hline & \multirow[t]{2}{*}{ Término lineal } & Ponderado & 5.159 & 1 & 5.159 & .185 & \multirow[t]{2}{*}{$\begin{array}{l}.670 \\
.818\end{array}$} \\
\hline & & Desviación & 120.336 & 8 & 15.042 & .540 & \\
\hline & Intra-grupos & & 975.305 & 35 & 27.866 & & \\
\hline & Total & & 1100.799 & 44 & & & \\
\hline \multirow[t]{5}{*}{ PH SALIVAL } & Inter-grupos & (Combinados) & 2.676 & 9 & .297 & 1.179 & .338 \\
\hline & Término lineal & Ponderado & .215 & 1 & .215 & .854 & .362 \\
\hline & & Desviación & 2.461 & 8 & 308 & 1.220 & .317 \\
\hline & Intra-grupos & & 8.827 & 35 & .252 & & \\
\hline & Total & & 11.503 & 44 & & & \\
\hline
\end{tabular}

En la tabla 6, se contrastaron ambas variables mediante la prueba paramétrica ANOVA: el Índice CPOD y el pH salival de los alumnos que participaron en el estudio. Se obtuvo un nivel de confianza $p$ de 0,280 , con un nivel de desviación de 0,52 . El nivel de confianza fue de $95 \%$.
Debido a que $p$ es mayor a 0,05 , se concluye que no existen diferencias significativas entre ambas variables.

Tabla 6. Relación del CPOD y el pH salival de los alumnos con habilidades diferentes con retardo mental del CASP _ 2013.

ANOVA de un factor

\begin{tabular}{|c|c|c|c|c|c|c|c|}
\hline & & & $\begin{array}{l}\text { Suma de } \\
\text { cuadrados }\end{array}$ & Gl & $\begin{array}{c}\text { Media } \\
\text { cuadrática }\end{array}$ & $\mathrm{F}$ & Sig. \\
\hline \multirow[t]{5}{*}{ PH SALIVAL } & Inter-grupos & (Combinados) & 6.776 & 26 & .261 & .993 & .517 \\
\hline & \multirow[t]{2}{*}{ Término lineal } & Ponderado & .326 & 1 & .326 & 1.243 & \multirow{2}{*}{$\begin{array}{l}.280 \\
.525\end{array}$} \\
\hline & & Desviación & 6.450 & 25 & .258 & .983 & \\
\hline & \multicolumn{2}{|l|}{ Intra-grupos } & 4.727 & 18 & .263 & & \\
\hline & \multicolumn{2}{|l|}{ Total } & 11.503 & 44 & & & \\
\hline \multirow[t]{5}{*}{$C P O D$} & Inter-grupos & (Combinados) & 1.313 & 26 & .050 & 1.730 & .116 \\
\hline & Término lineal & Ponderado & .009 & 1 & .009 & .295 & .594 \\
\hline & & Desviación & 1.304 & 25 & .052 & 1.787 & .104 \\
\hline & \multicolumn{2}{|l|}{ Intra-grupos } & .525 & 18 & .029 & & \\
\hline & \multicolumn{2}{|l|}{ Total } & 1.838 & 44 & & & \\
\hline
\end{tabular}

\section{DISCUSIÓN}

Para medir el $\mathrm{pH}$ de la saliva no estimulada de los alumnos con habilidades diferentes con retardo mental del Centro Ann Sullivan del Perú se empleó un Phmetro digital, previamente calibrado. Como resultado se obtuvo que la población muestreada presentó un $\mathrm{pH}$ salival relativamente neutro, con rangos entre 7,5 a 7,9 ; siendo los normales, en saliva de 6,5 a 7,0. Esto nos indica que la saliva de las personas con habilidades diferentes con retardo mental podría presentar una tendencia a la 
alcalinidad, lo cual significa que su función buffer evita una rápida desmineralización de la superficie dental, generando así la caries dental ${ }^{(18-20)}$.

Dichos resultados, asociados al Índice de Higiene Oral Simplificado según Greene \& Vermillion (IHOS) y al Índice CPOD, no marcaron una diferencia estadísticamente significativa obteniéndose un valor $p$ de 0,362 para el IHOS y de 0,280 para el Índice CPOD, respectivamente.

Con ello se concluye que el $\mathrm{pH}$ salival de las personas con habilidades diferentes con retardo mental no se encuentra relacionado directamente con los índices tomados en cuenta para el presente estudio. Relacionar ambas variables tuvo como finalidad demostrar la susceptibilidad de los alumnos con habilidades diferentes con retardo mental del CASP a desarrollar caries dental.

No existen estudios recientes que asocien el $\mathrm{pH}$ salival con el IHOS y CPOD en nuestro país; sin embargo, en el año 2012 Gómez y colaboradores realizaron un estudio similar en alumnos ingresantes a una universidad mexicana y hallaron que el $81,5 \%$ presentó un IHOS bueno. No obstante, los resultados del Índice CPOD fueron bastante altos según la OMS, lo que significa un grave problema de salud pública en estos adolescentes ${ }^{(14)}$. En comparación con Gómez y colaboradores, la presente investigación se llevó a cabo en una población con habilidades diferentes teniendo como condición que presentaran algún grado de retardo mental sin discriminar su profundidad, esto con la finalidad de evidenciar la vulnerabilidad de esta población a presentar mayor riesgo de caries dental y deficiente higiene bucal.

Resultando con un índice de higiene bucal regular y un índice CPOD muy bajo, Kumar y colaboradores en el año 2009 realizaron un estudio para analizar los indicadores del estado periodontal e higiene bucal en niños y adolescentes con retardo mental, para lo cual reunieron a 171 individuos, de una escuela en Udaipur, India(11) y se empleó el índice periodontal comunitario para evaluar el estado periodontal y el Índice de Higiene Oral Simplificado para evaluar la presencia de placa bacteriana en superficies dentales. El $87,7 \%$ de la población muestreada estuvo conformada por varones. Ellos dividieron a la población según su IQ para calcular el nivel de retardo mental en leve, moderado y severo; siendo el moderado el de mayor porcentaje con un $60,8 \%$ del total. Asimismo, para calcular el IHOS emplearon 3 rangos: bueno, regular y pobre, Resultando este último con mayor porcentaje, equivalente a una frecuencia de 107; es decir, representó al 62,6\% de la población.
Comparando la referida investigación con la presentada en este artículo, conviene indicar que la población seleccionada estuvo constituida por cuarenta y cinco (45) alumnos, todos residentes en Lima. No se discriminó a la población según el síndrome y/o condición que presentaba, ni el nivel de profundidad de retardo mental. Tampoco se evaluó el estado periodontal, pero sí el estado de higiene bucal mediante el IHOS, en el cual se consideraron rangos entre óptimo, regular, malo y muy malo. La categoría de IHOS Regular resultó con mayor representatividad en el presente estudio; asimismo, el valor IHOS registrado con mayor frecuencia fue de 2,0, que representa al $8,9 \%$ del total de la muestra.

De otro lado, Khocht y colaboradores, en el año 2010, realizaron un estudio en el que evaluaron a individuos de los hospitales regionales de Georgia, Atlanta y los dividieron en dos grupos: uno con personas con síndrome de Down y otro con personas con discapacidad mental sin síndrome de Down. A su vez fueron comparados con un grupo control sin ninguna discapacidad mental. Concluyeron que el grupo con discapacidad mental sin síndrome de Down presentaba mayor sangrado gingival, pérdida de inserción gingival y mayor número de piezas dentales ausentes en comparación con el de síndrome de Down sin discapacidad motora. Estos últimos a su vez, presentaron similares resultados al sondaje periodontal e índice de placa bacteriana comparados con los individuos del grupo control.

Es así que Khocht y colaboradores concluyeron que el estado de salud periodontal de los pacientes evaluados está asociado más a sus limitaciones físicas, en la medida que por tener una discapacidad motora no pueden realizar un buen cepillado dental y, por lo tanto, mantener una buena higiene bucal(5).

Relacionando el estudio de Khocht con la presente investigación realizada cabe mencionar que muchos de los alumnos del CASP presentaron alguna discapacidad motora agregada al retardo mental, dificultando así el hábito de mantener una higiene bucal óptima. No obstante, es pertinente mencionar que se vienen realizando charlas de instrucción tanto a padres de familia como alumnos para que puedan mantener un buen estado de higiene oral.

Asimismo, el presente estudio no contempla una evaluación periodontal mediante el sondaje, pero sí evidencia la presencia de placa bacteriana dura y blanda, a través del Índice de Higiene Oral Simplificado según Greene \& Vermillion, que registró con mayor frecuencia un IHOS de 2.0 según los patrones de la Organización Mundial de la 
Salud, cuyo resultado indica que en su mayoría los alumnos presentaban un índice regular de higiene bucal por falta de instrucción y carencia de habilidad motora para realizar un correcto cepillado dental ${ }^{(21,22) .}$

Por otro lado, en un estudio realizado en Nalgonda, India, Ameer y colaboradores evaluaron la higiene bucal y el estado periodontal de adolescentes con necesidades especiales. Dicho estudio fue bastante específico porque no sólo agrupó a jóvenes con habilidades especiales, sino que también comparó a quienes eran sordos, ciegos $y$ a quienes presentaban alguna discapacidad y/o limitación física, siendo estos últimos quienes representaron el $96 \%$ del total de la población con un estado periodontal e higiene bucal más deficiente en comparación con adolescentes ciegos, no verbales y/o sordos. En el citado estudio, se consideraron adolescentes de 14 hasta los 17 años, y se consiguió demostrar que un alumno no verbal o ciego se encuentra en plena capacidad de entender y aprender una correcta técnica de higiene bucal ${ }^{(4)}$.

Ahora bien, a diferencia del estudio citado, el mostrado en el presente artículo respecto al CASP tomó en cuenta a alumnos desde los 10 hasta los 50 años de edad, la mayoría representada por alumnos de 29 años $(11,1 \%)$, en la que se segmentó la población según el sexo, y que estuvo conformada por cuarenta y cinco (45) alumnos, de los cuales el $64,4 \%$ eran varones y el $35,6 \%$, mujeres.

Es menester indicar que el Centro Ann Sullivan del Perú también reúne a alumnos con otras condiciones tales como espina bífida, parálisis cerebral, alumnos no verbales, así como alumnos con problemas auditivos y visuales. Al respecto es importante sugerir que los alumnos que sufren de movimientos involuntarios 0 alguna otra discapacidad psicomotora más profunda reciban una atención más personalizada; así como la instrucción a sus padres y/o tutores quienes juegan un rol clave para el mantenimiento de su higiene personal, y por ende de la integridad de su salud(23,24).

Conviene subrayar que existen diversos factores determinantes que influyen en el mantenimiento de una higiene bucal óptima, haciendo a un individuo susceptible de desarrollar caries dental, gingivitis y otras enfermedades periodontales; entre ellos no sólo destaca el cepillado dental, sino también el pH salival(25). Sobre este último, aunque no se le atribuya la relevancia necesaria, la saliva juega un rol crucial en el estado de salud bucal, como se ha indicado debido a su capacidad buffer o función tampón. Así, cuando el pH salival tiende a ser más alcalino, el individuo presenta menor susceptibilidad a desarrollar caries dental.

Asimismo, numerosas investigaciones científicas han demostrado que cuando el $\mathrm{pH}$ alcanza un rango de 5,5, se produce la desmineralización del esmalte produciéndose la caries dental $(6,18,26,27)$. En adición a ello, es pertinente mencionar que recientes estudios demuestran que un ph salival con tendencia a la alcalinidad es más frecuente en individuos con enfermedad periodontal, siendo esta información propicia para el presente estudio ya que si bien no se utilizó algún índice para registrar el estado periodontal, se evidenció clínicamente la presencia de gingivitis aguda local y generalizada en la población de estudio ${ }^{(18,27)}$.

Considerando esta afirmación, Gouet realizó un estudio sobre los cambios de $\mathrm{pH}$ y flujo salival según el consumo de bebidas tipo Cola en estudiantes de pregrado de la Universidad del Desarrollo de Concepción, Chile. En esta investigación, la muestra fue dividida en grupos según frecuencia de consumo de bebidas gasificadas. El resumen estadístico del $\mathrm{pH}$ y flujo salival para cada uno de los tres niveles de consumo mostró diferencias significativas entre las medias y medianas de los distintos grupos.

Al respecto, Gouet concluyó que de acuerdo con lo señalado anteriormente, existe diferencia estadísticamente significativa entre las medias de $\mathrm{pH}$ y el flujo salival de un grado de consumo a otro con un nivel de confianza de $95 \%{ }^{(8)}$.

Realizando un contraste entre la investigación de Gouet y el presente estudio, cabe mencionar que a pesar de no haber interferido en el estado natural de la saliva recolectada de los alumnos del CASP con ninguna bebida carbonada, el pH de la población seleccionada tuvo una ligera tendencia a ser alcalina, teniendo una media de 7,7, con un nivel de confianza de $95 \%$, lo que significaría que el $\mathrm{pH}$ salival de las personas con habilidades diferentes no se encuentra necesariamente asociado a la vulnerabilidad de desarrollar caries dental| ${ }^{(22,27)}$.

Adicionalmente, en contraste con el autor, si bien en el estudio realizado a los alumnos del CASP, no se estudió el flujo salival, se llega a entender que a mayor consumo de bebidas carbonadas, menor será la capacidad buffer de la saliva, lo que determina una posible desmineralización del tejido del esmalte ${ }^{(28,29)}$.

Otro factor importante asociado al riesgo de desarrollar caries dental y enfermedad periodontal es el sustrato, en el que la dieta juega un rol determinante, por lo que teniendo en cuenta esto, 
Chuquimarca y Lara evaluaron la prevalencia de caries dental y su relación con el Ph salival en niños y adolescentes con discapacidad intelectual del Instituto Fiscal de Educación Especial, en Quito (octubre, 2016). En dicha evaluación usaron la prueba estadística chi-cuadrado de asociación e independencia la cual sirvió para determinar si el valor observado de una variable depende del valor observado de la otra variable. La muestra estuvo constituida por 155 niños y adolescentes con diversas condiciones tales como síndrome de Down, austismo, entre otras.

De este modo, luego de las pruebas correspondientes obtuvieron un nivel de significancia de $\mathrm{p}=0,027<0,05$ confirmando que existe una relación directa entre el $\mathrm{pH}$ salival y la experiencia de caries, pero que esta, a su vez, no está asociada a la discapacidad intelectual de los individuos participantes. Cabe mencionar que los registros de nivel de $\mathrm{pH}$ salival obtenidos en dicho estudio mostraban una tendencia mayor hacia valores alcalinos ${ }^{(30)}$.

Conforme se ha indicado, la dieta juega un rol determinante para evitar la formación de caries dental sobre todo en niños con alto riesgo cariogénico(31). Por ello, en las personas con habilidades diferentes es fundamental brindar la información necesaria, tanto a los educadores como a los padres de familia, para que puedan balancear los alimentos de sus hijos teniendo en cuenta que muchos de ellos tienen dificultades motoras para llevar a cabo un adecuado cepillado dental.

En tal sentido, relacionando el estudio de Chuquimarca y Lara, con la investigación presentada en este artículo, al emplear la prueba paramétrica de Anova con un nivel de confianza de $95 \%$ se obtuvo que, si bien el $\mathrm{pH}$ no guardó relación directa con el IHOS y CPOD, la mala técnica de cepillado dental sí influyó, y que de no ser así, la propia fermentación de alimentos (placa bacteriana) y formación de ácidos en la boca influiría en la disminución del $\mathrm{pH}$ salival haciéndolo más susceptible a una posible desmineralización del esmalte ${ }^{(30)}$.

Un reciente estudio llevado a cabo este año, 2017, por Balseca y Ospina en Ecuador ${ }^{(9)}$ tuvo como objetivo principal demostrar la efectividad de las topicaciones con agua de manzanilla para la estabilización del pH salival en personas con discapacidad intelectual. El estudio fue observacional, de carácter estadístico y biopsicosocial. Contrastando este estudio con el nuestro, el tamaño de muestra fue bastante similar, ya que las investigadoras observaron a 44 personas y el presente, a 45 . No obstante, se utilizaron distintos patrones para determinar la presencia de placa bacteriana sobre las superficies dentales: Índice de O'Leary e IHOS. Balseca y Ospina emplearon cintas reactivas de $\mathrm{pH}$ salival. En comparación con el presente estudio, se utilizó un pHmetro digital para registrar el valor del $\mathrm{pH}$ de saliva más exacto y así reducir el sesgo.

Los resultados en el estudio de las investigadoras, comprobaron que, mediante las topicaciones de agua de manzanilla en personas con discapacidad intelectual se produce una reducción de la placa bacteriana y mejoramiento de $\mathrm{pH}$ salival, pasando de $\mathrm{pH}$ salival moderadamente ácido a un $\mathrm{pH}$ que determina una saliva saludable. Obtuvieron un nivel de significancia menor a $0.05 \%$ con un nivel de confiabilidad de $95 \%$.

En contraste con la presente investigación, la naturaleza de la saliva no fue manipulada, dado que a pesar de ser un estudio descriptivo tuvo carácter retrospectivo. Fue importante mantener la integridad de las muestras de saliva no estimulada para asociarlas con el estado de higiene bucal. Es importante mencionar que está demostrado que la forma más eficaz para la remoción efectiva de placa bacteriana es través del cepillado dental(32). Las aplicaciones con manzanilla podrían estar más relacionadas con estabilizar la función tamponadora de la saliva en individuos en general, ya que no se halló relación directa estadísticamente con personas con discapacidad intelectual.

Con relación al Índice de Higiene Oral Simplificado, Hebbal y colaboradores, realizaron un estudio para determinar parámetros salivales asociados a caries dental y niveles de placa en individuos de 12 años de edad. Al respecto, de los 96 niños, 49 fueron varones y 47 mujeres. Se recolectó saliva estimulada y se evaluó el CPOD, determinando que las lesiones cariosas incipientes, agregadas a una capacidad deficiente buffer de la saliva, generan el incremento de población de Streptococcus Mutans y Lactobacillus $^{(12)}$.

En contraste con el estudio presentado en este artículo, este incluyó a 29 varones y 16 mujeres, desde los 10 años hasta los 50 años de edad. Por otro lado, la saliva recolectada fue no estimulada y no se estudió la formación de unidades bacterianas; sin embargo, sí se llegó a calibrar el pH salival empleando un pHmetro digital en cantidades aproximadas de saliva de $8 \mathrm{ml}$.

Asimismo, luego de realizar el Índice CPOD, se procedió a evaluar el IHOS (Greene \& Vermillion) teniendo como media el valor de 2,0 , equivalente a un índice de higiene bucal regular, según la Organización Mundial de la Salud. Además, se 
observó que en las caras vestíbulo-posteriores de las piezas superiores y la lingual-posterior de las inferiores hubo mayor cantidad de placa bacteriana dura.

Se concluye sobre la base de los resultados hallados que los alumnos del CASP no manejan correctamente la técnica de cepillado, así como que en algunos casos debe considerase su escasa habilidad psicomotriz debido a su condición y en otros, la falta de instrucción brindada para el correcto cepillado.

Es pertinente mencionar finalmente, que la correcta técnica de cepillado dental asegura el mantenimiento de una higiene bucal óptima, y con base en ello es crucial la generación de políticas públicas con una visión holística y familiar orientada a la educación de padres, cuidadores y profesores de alumnos con habilidades diferentes, con la finalidad de concientizarlos acerca de la importancia del mantenimiento de la salud bucal. Es oportuna y necesaria la formación de profesionales odontólogos orientados a instruir a ciudadanos con habilidades diferentes en técnicas de cepillado dental manual, con un espíritu de prevención y promoción de la salud.

Contribuciones de autoría: LLD participó en el diseño del estudio, recolección, análisis de resultados y redacción del artículo.

Fuente de financiamiento: autofinanciado.

Conflictos de interés: El autor declara no tener conflicto de interés en la publicación de este artículo.

\section{REFERENCIAS BIBLIOGRÀFICAS}

1. Usha M, Beena JP, Divya R. Importance of Oral Hygiene Habits in Mentaly Disabled Children. International Journal of Clinical Pediatric Dentistry. 2010;3(1): 39-42.

2. Huiracocha, L., Almeida, C. A., Huiracocha, K., Arteaga, A., Arteaga, J. A., Barahona, P., \& Quezada, J. E. Explorando los sentimientos de los padres, la familia y la sociedad a las personas con Síndrome de Down: Estudio Observacional. Maskana. 2015; 4(2): 47-57.

3. Medeiros A, Brindeiro du Araujo D, Feitosa V, Nascimiento W. Accessoao Cuidado em Saude Bucal para Criancas com Deficiencia Motora. Pes Bras Odontoped Clin Integral, Joao Pessosa. 2011;11(4): 593-599.

4. Ameer N, Palaparthi R, Neerudu M, Palakuru S, Singam H, Durvasula S. Oral hygiene and periodontal status of teenagers with special needs in the district of Nalgonda, India. Journal of Indian Society of Periodontology. 2012; 16(3): 421-425.
5. Khocht A, Janal M, Turner B. Periodontal health in Down syndrome: contributions of mental disability, personal and professional dental care. Specialist Care Dentista. 2010; 30(3):118-123.

6. Dominick P. Saliva : the precious body fluid. JADA. 2008;139(1): 5-6.

7. Jimenez R. Importancia del pH, flujo y viscosidad saliva sobre el desarrollo de caries dental en mujeres gestantes del primero trimester. Tesis de Bachillerato. Lima: Universidad Nacional Mayor de San Marcos; 2004.

8. Gouet R. Cambios en $\mathrm{pH}$ y flujo saliva según consume de bebidas cola en estudiantes. Revista Colombiana de Investigación en Odontología. 2011; 2(4): 15-23.

9. Ospina, L., Balseca, A.. (2017). Efectividad de la reducción de la placa bacteriana y del ph salival mediante topicaciones con agua de manzanilla en personas con discapacidad intelectual. Revista UCE (Ecuador). 2017; 93: 16-18.

10. Gutierrez M. Ortiz L, Medicina K, Chein S. Eficacia de una medida preventiva para el niño con riesgo cariogénico asociado a la estabilidad de $\mathrm{pH}$ salival. Revista Odontológica Sanmarquina. 2007; 10(1): 2527.

11. Kumar S, Sharma K, Duraiswamy P, Kulkarni S. Determinants for oral hygiene and periodontal status among mentally disabled children and adolescents. Journal of Indian Society of Periodontology. 2009; 3(27): 151-157.

12. Hebbal, M, Ankola A, Metgud S. Dental caries, salivary parameters and plaque scores as caries risk predictures among 12 years old school children. International Journal of Collaborative Research on Internal Medicine \& Public Health (India) 2012; 4(5): 544-550.

13. El $15 \%$ de la población peruana sufre de alguna discapacidad. Diario La República. http://www.larepublica.pe/17-06-2012/el-15-de-lapoblacion-peruana-sufre-de-alguna-discapacidad. Lima - Junio 2012.

14. Gomez N, Morales M. Determinación de los índices CPO-D E IHOS en estudiantes de la Universidad Veracruzana, Mexico. Revista Chilena Salud Pública. 2012;16(1): 26-31.

15. Sernaque R. Variación del flujo salival en niños asmáticos por el uso de inhaladores B2 andremérgicos. Tesis de Bachillerato. Lima: Universidad Nacional Mayor de San Marcos; 2004.

16. Carranza F. Periodontología Clínica 10ª edición. México: McGraw Hill-Interamericana; 2010.

17. Boj J, Catalá M, Garcia-Ballesta C, Mendoza A, Planells P. Odontopediatría la evolución del niño al adulto joven. Madrid: Ripano; 2011.

18. Dawes C. Salivary flow patterns and the health of hard and soft oral tissues. JADA 2008;139(1): 18-24.

19. Yoshihiro A, Masato S. Salivary defensins and their importance in Oral Health and Disease. Health Sciences University of Hokkaido (Saporo) 2007; 13: 3065-3072.

20. Yazigi R. Rincones olvidados de la Gastroenterología: las glándulas salivales y el papel en la saliva. Revista Gastroenterología Latinoamericana. 2006;17(2): 4249. 
21. Dreizen S. The role of diet in dental decay. Nutrition News EEUU. 1996; 29(1): 5-10.

22. Jaccarino J. Helping the Special Needs Patient Maintain Oral Health. The Dental Assistant. New Jersey. 2009; 78(3); 11-37.

23. Diagnostic and Statical Manual of Mental Disorders. DSW-IV-TR, 4ta edición. Washington: American Psychiatric Association; $2000 . \quad$ En: http://annsullivanperu.org/personas-con-habilidadesdiferentes.

24. Convención Internacional sobre los Derechos de Personas con Discapacidad. México: Conadis; 2007. En: http://www.conadis.salud.gob.mx/descargas/df/conve ncionsobrelosderechisdelaspersonascondiscapacidad .pdf

25. Ministerio de Salud, Gobierno de Chile Guía Clínica Atención Odontológica integral de la embarazada. http://es.scribd.com/veronica_mansilla/d/32997431/34 -anexo-7-indice-de-Higiene-Oral-Simplificado-deGreene-y-Vermillion

26. R.A.D. W. Bioquímica Dental Básica y Aplicada. 2ª ed. México D.F.: Editorial El Manual Moderno S.A.; 1982.

27. Burzynski S. Periodontal disease and Down syndrome patients. RDH Magazine (EEUU). 2012; 1(1): 28-30.

28. Negroni M. Microbiología estomatológica. Fundamentos y guía práctica. 2da. edición. Buenos Aires: Médica Panamericana; 2009.

29. Tanaka K. Dairy product and calcium intake during pregnancy and dental caries in children. Nutritional Journal. 2012;11(33): 1-8.

30. Chuquimarca, B., Lara, A. Estudio observacional de la prevalencia de caries dental y su relación con el $\mathrm{Ph}$ salival en niños y adolescentes con discapacidad intelectual del Instituto Fiscal de Educación Especial

- IFEE. Tesis de Postgrado. Especialidad Odontopediatría. Quito: Universidad Central del Ecuador; 2016.

31. Mahan K. Nutrición y Dietoterapia. México: McGraw Hill Interamericana;1995.

32. Plaque Physiology. en: www.ncl.ac.uk/dental/oralbio/oralnv/tutorials/stephanc urves1.htm. 